Article

\title{
Risk Perception and Property Value: Evidence from Tianjin Port Explosion
}

\author{
Yaoxuan Huang, Tsz Leung Yip *D and Cong Liang \\ Department of Logistics and Maritime Studies, The Hong Kong Polytechnic University, Hong Kong 999077, \\ China; yaoxuanhuang@hotmail.com (Y.H.); liang.cong@hotmail.com (C.L.) \\ * Correspondence: t.l.yip@polyu.edu.hk
}

Received: 23 December 2019; Accepted: 5 February 2020; Published: 6 February 2020

\begin{abstract}
This paper aims to investigate the perceived risk after the Tianjin port explosion event and its impact on property value. In addition to focusing on the relationship between homebuyers' risk perception and property sales price, this paper also considers the risk perception of property sellers via the sale-to-list ratio. By using the difference-in-differences method and the sample from the property agent, we found that the explosion event generated a long-time effect on the public and property market in the city of Tianjin. Relative to those properties far away from the explosion site, the sales price and the sale-to-list ratio of the property near the explosion site were detected to have significant drops for the first six months after the explosion event. The temporal decrease of the relative sales price and the sale-to-list ratio are the evidence of short period overreaction from the public, which decays over time. This study demonstrates an indirect method to estimate the perceived risk of the general public and provides valuable insight into sustainable port management policies.
\end{abstract}

Keywords: Tianjin port explosion; risk perception; property value; difference-in-differences; the housing market

\section{Introduction}

The occurrence of two massive explosions in the port of Tianjin city in China on 12 August 2015 is an unprecedented tragedy. The explosion not only led to 173 people dead, 8 missing, and over 700 non-fatally injured [1], it also devastated over 17,000 households, 779 businesses [2]. These two explosions resulted from the mismanagement and improper usage of the warehouse by storing and placing hazardous and flammable chemicals in the neighborhood of 11,000 tonnes, including calcium carbide, sodium cyanide, potassium nitrate, ammonium nitrate, and sodium nitrate. According to the report of the China Earthquake Networks, the power/energy of the first and second explosions are equivalent to 3 and 21 tons of TNT detonating, respectively [3]. The economic losses of these two explosions were estimated at around 70 billion RMB (i.e., 11 billion USD). Recalling the history of man-made insured losses records, the Tianjin port explosion gave rise to insurance losses of around 2.5 to 3.5 billion USD (in 2015), which ranks the top in Asia and the third in the world [4].

The massive explosions turned a prosperous Tianjin port into an apocalyptic scene overnight [5]. They brought about a long nightmare to the residents of the Tianjin port due to the pollutions generated from the hazardous chemicals. The Chinese government assigned three hundred military chemical experts to clean up the mess by using heavy machinery to build a large wall of earth and sand around the site to prevent the hazardous chemical materials (e.g., sodium cyanide) from spreading [6]. Nonetheless, the poisons remaining in the explosion zone or in water are still major safety concerns of the public as the remedy of the explosion site may require a long-time process. In this regard, the exposure to the hazardous environmental risk of the explosion site was likely perceived at a higher level. 
Research in behavioral economics and psychology have pointed out that perceived risk is distinguished from the actual risk assessed by experts [7-9]. As suggested by [10], the actual risk may be amplified from the public as the risk perception is primarily based on psychology emotions/intuition rather than a precise assessing of the actual risk. The cause of the amplified risk perception or overreaction is due to the aftermath/damage of this unexpected and rare event. The overreaction denotes the difference between the observed reaction and the expected outcome. To be more specific, the difference between the changes in the property sales price that occur before and after the event of the treatment and control group is considered to be an overreaction [11-15]. According to the prospect theory, rare events tend to be overweighed as it in the absence of the risk-learning process through repeated experience [16]. In this paper, an important question we would like to investigate is the degree to which the Tianjin port explosions affected the level of perceived risk of the public.

To tackle this question, we adopted an indirect method of using difference-in-differences (DID) models to examine the impact of the Tianjin port explosion on the property market. To the best of our knowledge, the Tianjin port explosion provides a unique setting to measure perceived risk to rare events because the threat of cyanide is at the top of the public's concern. A small amount of sodium cyanide can cause death to a human [17]. Unlike other rare events (e.g., pipeline explosion, earthquake and flooding) that have previously been studied, the environmental risk of the 2015 Tianjin port explosion shifted to a new high level.

This paper contributes to the extant literature on risk and property market in three ways. Firstly, our study is the first attempt to examine the impact of the Tianjin port explosion event on the public. Secondly, this paper investigates the risk perception of the homebuyer and home sellers and how they are affected after by the extreme local event, outside the U.S. and Europe. The property transaction behavior is not driven by market information only, but also by psychological factors such as emotions [18]. Thirdly, this is the first study to consider the risk perception of home sellers, which has been overlooked in the previous literature. The property sales price is seen as an agreement between home buyer and seller, which well reflects how much the buyer is willing to pay and the willingness of the seller to accept the offer from the buyer. However, the property sales price cannot reveal sellers' responses to extreme events without considering the list price. From a theoretical standpoint [19], when loss averse home sellers confront with the uncertainty and risk after an extreme event (e.g., explosion), they intend to sell the property with a high urgency, and thus do not set a low list price but set a low reservation price in order to yield a quick sale. However, the reservation price is unobservable and therefore, the previous literature used sales price as a substitution to the reservation price [19]. In this regard, the ratio of the sale price to the list price of the property near the explosion site would fall after the Tianjin port explosion. The utilization of this ratio could be useful to detect how property sellers overreact to an explosion event. The models are expected to provide valuable insight into and practical measure of the perceived risk of the general public.

The remainder of this paper is organized as follows. Following this brief introduction, Section 2 presents a review of the literature on the perceived risk of rare events in the housing context. Section 3 then addresses the research method. Section 4 describes the data sample and study area. Section 5 discusses the study results and Section 6 draws conclusions.

\section{Literature Review}

In studying the effect of a rare event on risk perception, property value/price is a useful proxy to denote the perceived risk. A residential property is valued for what surrounds it. The main assumption is that as the property market remains similar before and after the port accident, the property rates reflect the demand for the property and the unobserved perceived risk around the port. The investigation of perceived risk from the previous literature can be classified into two groups: direct and indirect methods. The direct methods usually rely on people's feedbacks by asking a series of well-defined structural questions. The response to the structural question in terms of the Likert scale indicates the people's risk perception, which well reflects the willingness to pay in response to changes in 
environmental amenities. However, direct methods seldom receive critical opinion towards the hypothetical nature of the structural questions as they do not cover people's actual behavior [20].

Indirect methods consider the consumers' decisions and preferences by the hedonic-price approach. The coefficients estimated in the hedonic-price approach indirectly reflect the buyers' marginal willingness to pay for the residential property in response to the specific external characteristics (or risk perception) [21,22]. In comparison with direct methods, indirect methods are less expensive and time-consuming to implement. Examples of these studies can be seen regarding the risk perception of rare events, such as flood risk, nuclear power, pipeline explosion, earthquake, and disease epidemic. The following examples of the literature are representative of previous research considering the relationship between risk perception and property value, but is by no means an exhaustive list.

Many studies have attempted to explore the capitalization effect of flood risk on property value. The recent work by Kousky [21] examined the capitalized effect of flood risk on property prices by considering a set of long samples documenting single-family residential property sales in St. Louis County between 1979 and 2006. The findings indicate that home buyers were willing to pay for living in a region that boasted of a low flood risk. Similarly, Votsis and Perrels [22] investigated the relationship between flood risk information disclosure and property prices in three cities, namely Helsinki, Pori and Rovaniemi in Finland. They found that housing prices located in floodplains were detected to significantly drop after the flood risk information was disclosed. These two studies, however, did not cover the aspects of overreaction or fear of rare events.

In addition to flood risk, the capitalization effect of nuclear power on land markets or property markets was witnessed after the Fukushima Nuclear Accident in 2011. The research conducted by Zhu, Deng, Zhu and He [23] examined the impact of the 2011 Fukushima Nuclear Accident on risk perception towards nuclear power in China. Using a set of land transaction records for the empirical analysis, they found that the land transaction price was reduced by $18 \%$ one month after the accident, indicating that the impact of the 2011 Fukushima Nuclear Accident decayed over time. Similar research performed by Bauer, Braun and Kvasnicka [14] studied the effect of Germany's energy policy on housing value, where the policy change was due to the 2011 Japan Nuclear Accident. They found that housing prices near nuclear power plants that were shut down right after the accident dropped by $9.8 \%$. They explained that the detriment to the housing originated from the changes in the local labor market by shutting down nuclear plants.

Another contribution to the literature of risk perception on the property market comes from the work of Freybote and Fruits [18], where they investigated the relationship between the perceived risk of home buyers and the construction stage of the underground pipeline. Media coverage of pipelines in different construction stages was served as a proxy to measure the overreaction/fear of the potential risk of the pipeline explosion. They found that a higher perceived risk reduces sales prices once the pipeline is in operation. Hansen, Benson and Hagen [24] studied the effect of the proximity to the site of the pipeline on the housing value by using a set of the housing data of Bellingham, Washington. They corroborated that pipeline site would not be a public concern to generate potential risk to the neighboring community provided that the event of the pipeline explosion was not dug out and reported. The intensive media report is the major reason that drove the public overreaction. However, this effect would decay over time, which is in line with other studies of overreactions.

The perceived risk of earthquakes and disease epidemics have also been carried out. Deng, Gan and Hernandez [25] considered the perceived risk of the earthquake by investigating the relationship between the floor level and housing value. A unique set of new apartments was used to conduct the research. They found that relative housing prices of low to high floor apartments significantly increased after the Wenchuan earthquake in May 2008. These important findings indicate that the overreaction/fear of the earthquake is short-term behavior which will gradually dissipate in the long run. Wong [26] considered the public reaction to the Hong Kong Severe Acute Respiratory Syndrome (SARS) epidemic in 2003. A large set of the housing transaction record, including the housing value and housing volume, are investigated in Wong's research. She found that the market was surprisingly 
cautious and rational by holding the wait-and-see attitude in response to the SARS epidemic, which shows no overreaction.

In summary, there is plenty of research documenting the impact of perceived risk on property values, yet such a rich set of existing literature mainly covers the U.S. and European markets. Limited research can be seen elsewhere. Another shortcoming can also be seen from the previous literature that the perceived risk of rare events from the angle of home buyers are extensively discussed but with limited research focuses on home sellers' risk perception. In this paper, we investigated the perceived risk by considering the effect of the distance to the Tianjin port explosion site on property values, covering both home buyers' and sellers' sides.

\section{Research Methods}

As inspired by previous studies that used the indirect method to study risk perception $[11,12,14$, 20,22,24-26], we hypothesize that the property price reflects the demand for property and perceived risk. Since the demand for property is not significantly impacted by the port accident, the investigation of the impact of the Tianjin port explosion on the neighboring property prices will be conducted by adopting the difference-in-differences (DID) approach. DID suits to study the risk perception of Tianjin port explosion. This is mainly due to the DID followings a less strict exchangeability assumption [27], that is in absence of the Tianjin port explosion, the unobserved difference between treatment (properties in the explosion zone) and control group (properties are outside the explosion zone) are the same over time. By using the data from ex-explosion and post-explosion when randomization is not possible, DID enables to remove the biases in the post-explosion period comparison between the treatment group and the control group. The mathematical equation is presented as follows:

$$
\ln \left(Y_{i t}\right)=\beta_{1} X_{i t}+\beta_{2} \text { Explosion }_{i}+\gamma \text { Time }+\delta\left(\text { Explosion }_{\mathrm{i}} \times \text { Time }\right)+\alpha+\varepsilon_{i t}
$$

where $Y_{i t}$ refers to the sales price of property $i$ in month $t, X_{i t}$ is the vector documenting housing attributes. Explosion ${ }_{i}$ is the binary variable, which equals to one if the property $i$ is located near the Tianjin port explosion zone (i.e., within $5 \mathrm{~km}$, in this study) or zero if not. Time is also a dummy variable, which equals to one if property transaction after the Tianjin port explosion or zero if before, $\alpha$ is constant, and $\varepsilon_{i t}$ is error term. $\beta_{i}(i=1,2)$ and $\gamma$ are coefficients.

To be more specific, the coefficient $\delta$ is of particular interest in this study as it reveals the average treatment effect by measuring the differences before and after the explosion in terms of the changes of average housing prices that are in the vicinity to and further away from the explosion site. The vector $X_{i t}$ is used for controls of housing attributes. Two groups of housing attributes were selected for capturing the observable property characteristics, including structural attributes and service attributes. The first group of housing attributes includes the age of the property, the size of the property, the floor of the property, the number of living rooms in the property, whether it is an elevator-equipped property (dummy variable), and the decoration of the property (dummy variable). The variables in the second group denote the availability of having access to public services such as public transport services (e.g., metro, bus), a hospital, a park, a school, and a central business district (CBD).

In addition to the average treatment effect, we are also interested in investigating how strongly and quickly the property market responded to the Tianjin port explosion. For this purpose, Equation (1)

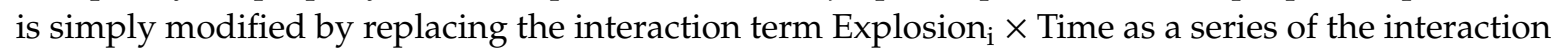
terms, where the detailed form is presented in Equation (2):

$$
\ln \left(\mathrm{Y}_{\mathrm{it}}\right)=\theta_{1} \mathrm{X}_{\mathrm{it}}+\theta_{2} \text { Explosion }_{\mathrm{i}}+\Sigma_{\mathrm{j}} \gamma_{\mathrm{j}} \text { TimeM }_{\mathrm{j}}+\Sigma_{\mathrm{j}} \delta_{\mathrm{j}}\left(\text { Explosion }_{\mathrm{i}} \times \text { TimeM }_{\mathrm{j}}\right)+\zeta+\xi_{\mathrm{it}}
$$

where $Y_{i t}, X_{i t}$, and Explosion ${ }_{i}$ are identical to that of Equation (1). Time $M_{j}$ is the dummy variable, indicating that the transaction time of the property is $\mathrm{j}$ month(s) after the Tianjin port explosion, $\delta_{\mathrm{j}}$ is the coefficient detecting the $j$-th month treatment effect of the post-explosion. Notations $\zeta$ and $\xi_{i t}$ are the constant and error terms of Equation (2), respectively. 
In addition to the above two empirical strategies, this paper also intends to investigate the risk perception of property sellers responding to an explosion event in Tianjin port. To consider this issue, the dependent variable of the above equations is replaced by the ratio of the sales price to the list price of the property (hereafter sale-to-list ratio). The specific empirical models are presented as follows:

$$
\begin{gathered}
Y_{\text {it }}^{\text {sales }} / Y_{i t}^{\text {list }}=\beta_{1}^{\text {seller }} X_{i t}+\beta_{2}^{\text {seller }} \text { Explosion }_{i}+\gamma^{\text {seller }} \text { Time }+\delta^{\text {seller }}\left(\text { Explosion }_{i} \times \text { Time }\right)+\alpha^{\text {seller }}+\varepsilon_{i t}^{\text {seller }} \\
Y_{i t}^{\text {sales }} / Y_{i t}^{\text {list }}=\theta_{1}^{\text {seller }} X_{i t}+\theta_{2}^{\text {seller }} \text { Explosion }_{i}+\Sigma_{j} \gamma_{j}^{\text {seller }} \operatorname{TimeM}_{j}+\Sigma_{j} \delta_{j}^{\text {seller }}\left(\text { Explosion }_{i} \times \text { TimeM }_{j}\right)+\zeta^{\text {seller }}+\xi_{i}^{\text {seller }}
\end{gathered}
$$

where $Y_{i t}, X_{i t}$, and Explosion ${ }_{i}$ hold the same as that in Equations (1) and (2). $\beta_{i}^{\text {seller }}(i=1,2), \gamma^{\text {seller }}, \delta^{\text {seller }}$, $\alpha^{\text {seller }}, \theta_{i}^{\text {seller }}(i=1,2), \gamma_{j}^{\text {seller }}, \delta_{j}^{\text {seller }}$ and $\zeta^{\text {seller }}$ are the coefficients corresponding to Equations (3) and (4), respectively. The superscript "seller" is used in order to distinguish from that of Equations (1) and (2).

\section{Data}

The sample we collected for this study was from one of the famous property agents, Lianjia, in China, which dominates the greatest market share for information on property transactions. The dataset is a non-public source which consists of 11,935 second-hand domestic housing data, covering 36 months from March 2014 to February 2017. This set of sample data includes both property sales prices and the initial list price.

Except for the sales price and list price, a bundle of property characteristics (e.g., physical structure, accessibility to public services and views) that would capture the level of satisfaction to the potential buyers and sellers should also include for the following empirical analysis. On searching the information from the open data source, OpenStreetMap, we can only collect the information as regards the physical structure attributes and accessibility to public services, whereas the other information, such as views, is not available. In this regard, two groups of attributes, namely structural attributes and environmental attributes, are also included in this paper in order to control the characteristics of the properties (Table 1). The first group of attributes includes the basic information of the property, such as the size of the apartment, age of apartment, the floor of the apartment, and the number of living rooms. The second group of attributes refers to the proximity of external services/facilities such as a park, hospital, fire station, police office, transportation (e.g., bus and railway), business (e.g., CBD) and education (e.g., primary school). The term proximity is proxied as the closest distance between the property and a specific service, which is measured by using ArcGis@10.3 (Figure 1).

It is worth mentioning that the explosion zone we considered in this paper is a distance of $5 \mathrm{~km}$ from the explosion site. The control group was selected as the properties with a distance to the explosion site between $\sim 20 \mathrm{~km}$ and $\sim 50 \mathrm{~km}$. The selection of $5 \mathrm{~km}$ as the explosion zone was made according to the existing literature [28] and news report [29]. The study conducted by Smolen et al. [28] disclosed that a significant range of the toxic chemical waste site on the property value is around 5.75 miles (i.e., $9.25 \mathrm{~km}$ ), with no further effect beyond this range. On the other hand, the news reported: "the strong wave smashed and affected the area about $3 \mathrm{~km}$ around the Tianjin Port explosion site" [29] since the new report covers the short-term or instant impact from the explosion, while the risk perception of the home buyers and home sellers may even cover a broader range. Therefore, to be conservative, we select $5 \mathrm{~km}$ as an explosion zone. In the next empirical section, we provide a robust legitimacy check for selecting the $5 \mathrm{~km}$ explosion zone. 


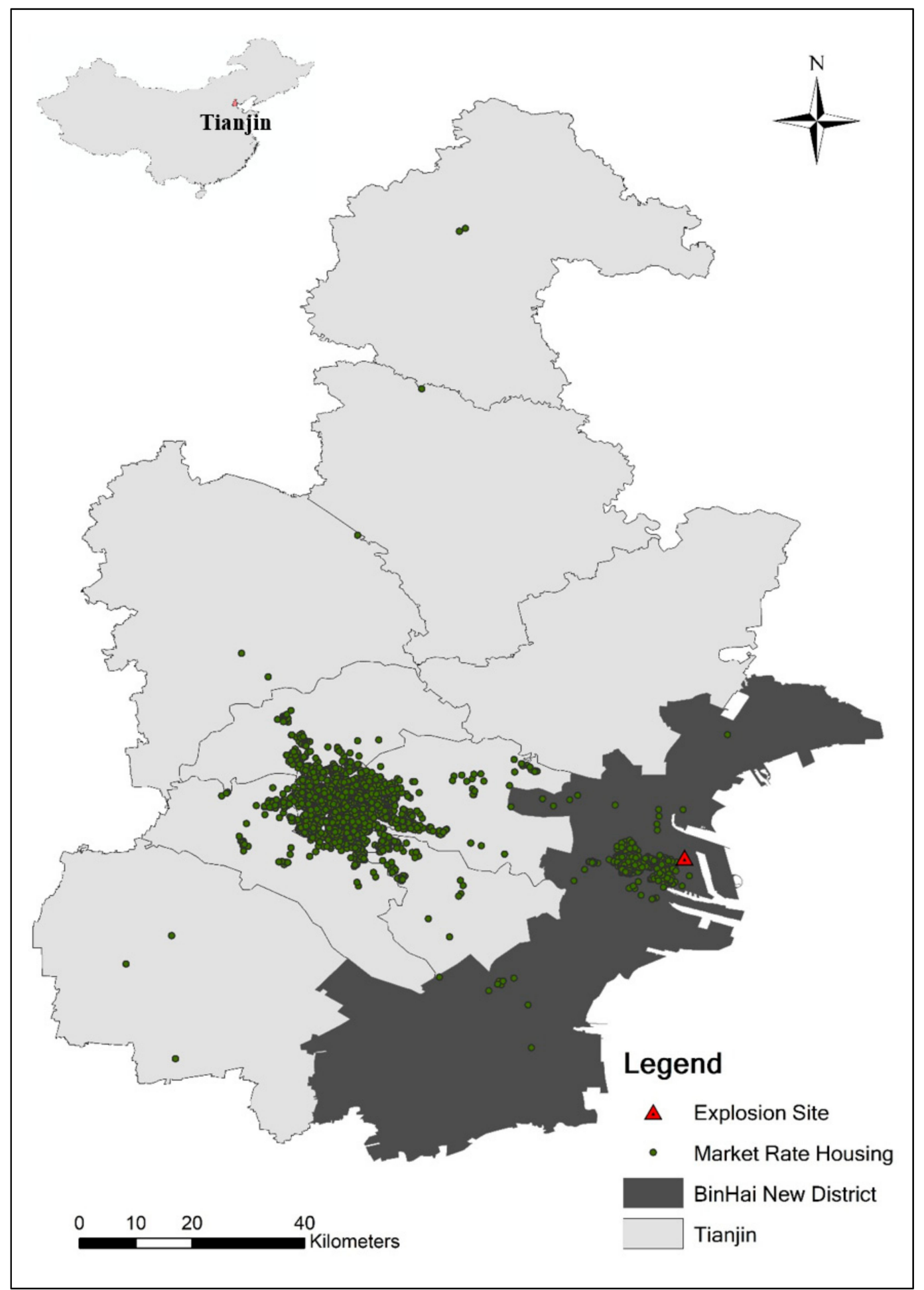

Figure 1. Tianjin port explosion site and distribution of domestic housing. 
Table 1. Summary of variables.

\begin{tabular}{|c|c|c|}
\hline Variables & Description & Unit \\
\hline Sales price & Sales price of property & RMB (million) \\
\hline List price & The initial list price of the property & RMB (million) \\
\hline Sales/List & Ratio of property sales price to list price & Percentage \\
\hline Area & Size of the apartment & Square meters \\
\hline Floor & The floor on which the apartment is located & Count \\
\hline Rooms & Number of Rooms in the property & Count \\
\hline Age & Age of the apartment (in years) & Count \\
\hline Decoration & Whether the apartment is well decorated & 1 or 0 \\
\hline Elevator & Whether the apartment is equipped with an elevator & 1 or 0 \\
\hline CBD & The distance to the nearest central business district & 100 meters \\
\hline Fire station & The distance to the nearest fire station & 100 meters \\
\hline Bus stop & The distance to the nearest bus stop & 100 meters \\
\hline Hospital & The distance to the nearest hospital & 100 meters \\
\hline Railway & The distance to the nearest railway station & 100 meters \\
\hline Park & The distance to the nearest park & 100 meters \\
\hline Police station & The distance to the nearest police station & 100 meters \\
\hline School & The distance to the nearest public primary school & 100 meters \\
\hline Time & $\begin{array}{l}\text { Dummy variable, } 1 \text { denotes transaction of the property is } \\
\text { after the explosion, } 0 \text { otherwise }\end{array}$ & 1 or 0 \\
\hline Explosion & $\begin{array}{c}\text { Dummy variable, } 1 \text { indicates the property is located inside } \\
\text { the explosion zone, } 0 \text { otherwise }\end{array}$ & 1 or 0 \\
\hline Explosion $\times$ Time & $\begin{array}{l}\text { Dummy variable, } 1 \text { denotes the transaction of the property } \\
\text { inside the explosion zone that is after the date of explosion, } \\
0 \text { otherwise }\end{array}$ & 1 or 0 \\
\hline
\end{tabular}

The descriptive statistics of the selected variables are summarized in Table 2. It details the information, such as sale price, list price, sale-to-list ratio and other control variables before and after the explosion for the property located at less than $5 \mathrm{~km}$ and further than $5 \mathrm{~km}$ from the explosion site. Upon comparing the descriptive statistics in Table 2, the average level of the sales price, list price shows an uprising trend from before and after the explosion for that property within $5 \mathrm{~km}$ and outside $5 \mathrm{~km}$ of the explosion site. The number in column (5) in Table 2, which serves as an unconditional estimate of DID, displays the preliminary results. The DID of the sales price (e.g., Sales price and $\ln$ (Sales price) in Table 2) seems to be significantly different from zero while the list price holds the opposite result. Interestingly, the sale-to-list ratio (e.g., Sale/List) within $5 \mathrm{~km}$ of the explosion site follows a decline tendency when comparing the before and after explosion statistics (e.g., column (1) and (3)). The changes in the ratio may imply the overreaction behavior of the property seller after the explosion, which deserves our consideration in the following empirical studies.

Table 2. Summary of descriptive statistics before and after the Tianjin port explosion.

\begin{tabular}{|c|c|c|c|c|c|}
\hline \multirow[b]{2}{*}{ Variable } & \multicolumn{2}{|c|}{ Before the Explosion } & \multicolumn{2}{|c|}{ After the Explosion } & \multirow{2}{*}{$\begin{array}{c}\text { DID } \\
{[(3)-(1)]-[(4)-(2)]}\end{array}$} \\
\hline & $\begin{array}{l}\text { Distance to } \\
\text { Explosion Site } \\
<5 \mathrm{~km}\end{array}$ & $\begin{array}{l}\text { Distance to } \\
\text { Explosion Site } \\
\geq 5 \mathrm{~km}\end{array}$ & $\begin{array}{l}\text { Distance to } \\
\text { Explosion Site } \\
\quad<5 \mathrm{~km}\end{array}$ & $\begin{array}{l}\text { Distance to } \\
\text { Explosion Site } \\
\quad \geq 5 \mathrm{~km}\end{array}$ & \\
\hline & (1) & (2) & (3) & (4) & (5) \\
\hline Sales price & $1.197(0.635)$ & $1.823(1.471)$ & $1.395(0.874)$ & $2.327(1.505)$ & -0.306 \\
\hline List price & $1.321(0.629)$ & $1.880(1.509)$ & $1.844(0.996)$ & $2.407(1.561)$ & -0.004 \\
\hline Ln (Sale price) & $2.271(0.479)$ & $2.576(0.819)$ & $2.491(0.516)$ & $2.959(0.624)$ & -0.163 \\
\hline Sale/List & $0.829(0.177)$ & $0.965(0.045)$ & $0.781(0.221)$ & $0.966(0.048)$ & -0.049 \\
\hline Size & $90.092(35.408)$ & $83.443(55.810)$ & $83.566(33.526)$ & $88.043(44.091)$ & -11.126 \\
\hline Age & $10.596(9.873)$ & $9.219(10.838)$ & $9.868(7.459)$ & $9.774(7.622)$ & 1.283 \\
\hline Floor & $17.605(13.469)$ & $16.966(14.365)$ & $13.994(11.229)$ & $12.598(11.121)$ & 0.757 \\
\hline Rooms & $3.109(0.948)$ & $3.055(1.443)$ & $3.155(1.095)$ & $2.698(1.142)$ & 0.403 \\
\hline
\end{tabular}


Table 2. Cont.

\begin{tabular}{|c|c|c|c|c|c|}
\hline \multirow[b]{2}{*}{ Variable } & \multicolumn{2}{|c|}{ Before the Explosion } & \multicolumn{2}{|c|}{ After the Explosion } & \multirow{2}{*}{$\frac{\text { DID }}{[(3)-(1)]-[(4)-(2)]}$} \\
\hline & $\begin{array}{l}\text { Distance to } \\
\text { Explosion Site } \\
\quad<5 \mathrm{~km}\end{array}$ & $\begin{array}{l}\text { Distance to } \\
\text { Explosion Site } \\
\quad \geq 5 \mathrm{~km}\end{array}$ & $\begin{array}{l}\text { Distance to } \\
\text { Explosion Site } \\
\quad<5 \mathrm{~km}\end{array}$ & $\begin{array}{l}\text { Distance to } \\
\text { Explosion Site } \\
\quad \geq 5 \mathrm{~km}\end{array}$ & \\
\hline & (1) & (2) & (3) & (4) & (5) \\
\hline Fire station & $20.713(12.227)$ & $23.755(18.642)$ & $21.630(19.728)$ & $25.879(22.162)$ & -1.207 \\
\hline Park & $19.484(16.912)$ & $18.807(13.916)$ & $19.324(15.399)$ & $19.059(14.531)$ & -0.412 \\
\hline Hospital & $18.593(13.297)$ & $14.972(12.871)$ & $20.362(16.919)$ & $18.855(14.989)$ & -2.114 \\
\hline Railway & $16.455(8.789)$ & $13.928(10.950)$ & $17.264(11.434)$ & $14.550(11.765)$ & 0.187 \\
\hline School & $13.673(8.544)$ & $12.142(10.241)$ & $14.488(10.532)$ & $13.512(10.094)$ & -0.555 \\
\hline Police station & $23.271(15.442)$ & $27.569(19.633)$ & $23.699(16.821)$ & $27.951(23.399)$ & 0.046 \\
\hline Bus station & $19.838(10.126)$ & $14.169(11.718)$ & $21.242(12.515)$ & $16.254(12.445)$ & -0.681 \\
\hline CBD & $38.097(28.252)$ & $26.308(21.532)$ & $36.013(28.027)$ & $25.801(19.219)$ & -1.577 \\
\hline Observations & 2896 & 3475 & 2029 & 3535 & 11935 \\
\hline
\end{tabular}

\section{Results and Empirical Findings}

\subsection{Main Results}

The main results are summarized in Table 3. Inspired by the descriptive statistics in Table 2, we consider the unconditional DID estimate (i.e., Model 1 in Table 3) without considering the property-related attributes. All coefficients of Model 1 in Table 3 are significant but with a low goodness-of-fit (R-Squared with 0.1129 in Table 3) and a large magnitude of intercept (4.879 in Table 3), indicating that some variables are missing in Model 1. In this regard, the property structural attributes are supplemented for estimating the second model (Model 2, the third column of Table 3). Again, all the coefficients are statistically significant. The coefficient of goodness-of-fit rises to 0.5603 and the average treatment effect (i.e., Explosion $\times$ Time) changes slightly from -0.162 to -0.227 . On seeing that the estimation accuracy would improve by incorporating the property structural attributes, we then supplement environmental attributes to consider the potential changes in property sales price over time. The results are statistically and economically significant at $5 \%$ and the goodness-of-fit coefficient further rockets to 0.6889 . The sign of the estimated coefficients of property attributes is consistent with that of the majority of studies in the housing literature. By comparing the results of these three models, the changes of variables in the group of treatment effects, including Time, explosion and Explosion $x$ Time are trivial, meaning that the results are stable across specifications. The significant coefficient of the average treatment effect shows that the property sales price within $5 \mathrm{~km}$ of the explosion site relative to those properties further away from the explosion site decline around 23.9\% (Model 3 in Table 3) after the explosion event. A possible explanation is that people in Tianjin city were afraid of/unwilling to living within $5 \mathrm{~km}$ of the explosion site after the explosion event.

Table 3. Main results of the estimation.

\begin{tabular}{cccc}
\hline Variables & Model 1 & Model 2 & Model 3 \\
\hline Treatment effect & & & \\
\hline Time & $0.383(0.014)^{* * *}$ & $0.519(0.009)^{* * *}$ & $0.553(0.008)^{* * *}$ \\
Explosion & $-0.305(0.023)^{* * *}$ & $-0.506(0.014)^{* * *}$ & $-0.459(0.016)^{* * *}$ \\
Explosion $\times$ Time & $-0.162(0.028)^{* * *}$ & $-0.227(0.018)^{* * *}$ & $-0.239(0.017)^{* * *}$ \\
\hline Control variables & & & \\
\hline Intercept & $4.879(0.011)^{* * *}$ & $1.068(0.035)^{* * *}$ & $1.462(0.266)^{* * *}$ \\
Size & & $0.087(0.010)^{* * *}$ & $0.088(0.010)^{* * *}$ \\
\hline
\end{tabular}


Table 3. Cont.

\begin{tabular}{cccc}
\hline Variables & Model 1 & Model 2 & Model 3 \\
\hline Age & & $-0.056(0.004)^{* * *}$ & $-0.039(0.007)^{*}$ \\
Floor & $0.008(0.002)^{* * *}$ & $0.025(0.003)^{* * *}$ \\
Rooms & $0.044(0.004)^{* * *}$ & $0.051(0.004)^{* * *}$ \\
Fire station & & $0.013(0.062)^{*}$ \\
Park & & $-0.023(0.005)^{*}$ \\
Hospital & & $0.016(0.007)^{* * *}$ \\
Railway & & $-0.049(0.004)^{* * *}$ \\
School & & $-0.059(0.001)^{* *}$ \\
Police station & & $0.045(0.009)^{* * *}$ \\
Bus & & $-0.014(0.001)^{* * *}$ \\
CBD & & $-0.041(0.007)^{* * *}$ \\
\hline R-Squared & 0.1129 & & 0.6889 \\
Adj R-Squared & 0.1127 & 0.5603 & 0.6885 \\
F-statistics & $506.18^{* * *}$ & $1897.42^{* * *}$ & $1614.311^{* * *}$ \\
\hline
\end{tabular}

Note: ${ }^{*} p<0.05,{ }^{* *} p<0.01,{ }^{* * *} p<0.001$, the number in parentheses is the standard error of the estimated result. The dependent variable of the above three models is the logarithm of the property sales price.

\subsection{Robust Check}

The aforementioned selection of the $5 \mathrm{~km}$ explosion zone needs further examining to confirm its legitimacy. A robust check is necessary. If the effects of the explosion cover the range of over $5 \mathrm{~km}$, then the estimation may underestimate the explosion effect and generate the bias results. To assess this issue, the explosion zone was then extended to $15 \mathrm{~km}$. Specifically, the properties located in the explosion zone were divided into three sub-groups, $0 \sim 5 \mathrm{~km}, 5 \sim 10 \mathrm{~km}$ and $10 \sim 15 \mathrm{~km}$. The control group remains as the properties located around $20 \sim 50 \mathrm{~km}$ from the explosion site. The estimation results of these three scenarios are displayed in Table 4 . The results of the first column in Table 4 is the same as Model 3 in Table 3, which is set as the baseline model. It is straightforward to see that the average treatment effects are statistically insignificant for Model 2 and Model 3, the exception being Model 1. It is also interesting to see that the scale or magnitude of the average treatment effect is negatively associated with the distance to the explosion site. In other words, the further the property is located, the smaller the magnitude of the estimated coefficients. The results in Table 4 show that the cutoff point of $5 \mathrm{~km}$ is legitimate and reasonable.

Table 4. Robust check I-DID estimates with different treatment groups.

\begin{tabular}{cccc}
\hline & Model 1 & Model 2 & Model 3 \\
\hline Treatment Group & $0 \sim 5 \mathrm{~km}$ & $5 \sim 10 \mathrm{~km}$ & $10 \sim 15 \mathrm{~km}$ \\
Control Group & $20 \sim 50 \mathrm{~km}$ & $20 \sim 50 \mathrm{~km}$ & $20 \sim 50 \mathrm{~km}$ \\
\hline Time & $0.553^{* * *}$ & $0.482^{*}$ & $0.377^{*}$ \\
& $(0.008)$ & $(0.058)$ & $(0.084)$ \\
Explosion & $-0.459^{* * *}$ & -0.134 & -0.088 \\
& $(0.016)$ & $(0.097)$ & $(0.116)$ \\
Explosion $\times$ Time & $-0.239^{* * *}$ & -0.193 & -0.119 \\
& $(0.017)$ & $(0.124)$ & $(0.141)$ \\
Structural Attributes & Yes & Yes & Yes \\
Environmental Attributes & Yes & Yes & Yes \\
\hline R-Squared & 0.6889 & 0.6361 & 0.6003 \\
Adj R-Squared & 0.6885 & 0.6356 & 0.5998 \\
F-statistics & $1614.31^{* * *}$ & $967.79 * * *$ & $1085.37^{* * *}$ \\
\hline
\end{tabular}

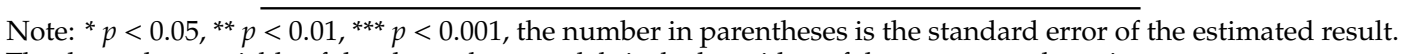
The dependent variable of the above three models is the logarithm of the property sales price.

In addition to the robust check of selecting the explosion zone above, it also needs to check the assumption of DID estimation. If the assumption is valid, then the estimation results are unbiased. 
In other words, the sales price of the properties in the treatment group (within $5 \mathrm{~km}$ of explosion site) and the control group (20 50 km away from the explosion site) should share a common time trend before the explosion happened. The estimation results are shown in Table 5. The empirical strategy in Model 1 in Table 5 is conducted by following the study of Bauer et al. [14], which simply modifies Equation (1) by supplementing the interaction terms (e.g., interacting the time dummies of each month before explosion, covering the period from April 2014 to February 2017 and the dummy of the explosion zone). The results demonstrate that the treatment effect for each month before the explosion event is not statistically significant, which echoes with the assumption of DID. By the same token, we then add these interaction terms to Equation (2) to further investigate the validity of the DID assumption. The results are depicted in column (2) in Table 5. Similar to Model 1, all the treatment effects before the explosion event are insignificant. Therefore, the results of Model 1 and Model 2 in Table 5 corroborate with the property sales prices of the treatment group and the control group, which do not follow different time trends before the explosion event.

Table 5. Robust check II-with treatment lead and lag effects.

\begin{tabular}{|c|c|c|c|}
\hline & Model 1 & Model 2 & Model 3 \\
\hline \multicolumn{4}{|l|}{ After explosion: } \\
\hline Explosion $\times$ Time & $-0.213(0.058)^{* * *}$ & & \\
\hline Explosion $\times$ TimeM $_{1}(2015.09)$ & & $-0.374(0.037)^{* * *}$ & $-0.313(0.028) * * *$ \\
\hline Explosion $\times$ TimeM $_{2}(2015.10)$ & & $-0.369(0.050)^{* * *}$ & $-0.301(0.045)^{* * *}$ \\
\hline Explosion $\times$ TimeM $_{3}(2015.11)$ & & $-0.396(0.052) * * *$ & $-0.337(0.047)^{* * *}$ \\
\hline Explosion $\times$ TimeM $_{4}(2015.12)$ & & $-0.383(0.053)^{* * *}$ & $-0.324(0.045) * * *$ \\
\hline Explosion $\times$ TimeM $_{5}(2016.01)$ & & $-0.275(0.059)^{* * *}$ & $-0.203(0.055) * * *$ \\
\hline Explosion $\times$ TimeM $_{6}(2016.02)$ & & $-0.324(0.045)^{* * *}$ & $-0.261(0.039) * * *$ \\
\hline Explosion $\times$ TimeM $_{7}(2016.03)$ & & $-0.152(0.037) * * *$ & $-0.098(0.039)^{* *}$ \\
\hline Explosion $\times$ TimeM $_{8}(2016.04)$ & & $0.138(0.066) *$ & $0.189(0.063) * *$ \\
\hline Explosion $\times$ TimeM $_{9}(2016.05)$ & & $-0.051(0.070) *$ & $-0.035(0.067)^{* *}$ \\
\hline Explosion $\times$ TimeM $_{10}(2016.06)$ & & $-0.101(0.091) *$ & $-0.044(0.091)^{* *}$ \\
\hline Explosion $\times$ TimeM $_{11}(2016.07)$ & & $-0.028(0.067) *$ & $0.006(0.091) *$ \\
\hline Explosion $\times$ TimeM $_{12}(2016.08)$ & & $0.209(0.230)$ & $0.065(0.235)$ \\
\hline Explosion $\times$ TimeM $_{13}(2016.09)$ & & $0.349(0.062) * * *$ & $0.244(0.059) * * *$ \\
\hline Explosion $\times$ TimeM $_{14}(2016.10)$ & & $0.543(0.389) *$ & $0.346(0.042) *$ \\
\hline Explosion $\times$ TimeM $_{15}(2016.11)$ & & $0.133(0.392)$ & $-0.121(0.399) *$ \\
\hline Explosion $\times$ TimeM $_{16}(2016.12)$ & & $0.488(0.089) * * *$ & $0.447(0.186)^{* * *}$ \\
\hline Explosion $\times$ TimeM $_{17}(2017.01)$ & & $0.309(0.364) *$ & $0.317(0.399)$ \\
\hline Explosion $\times$ TimeM $_{18}(2017.02)$ & & $0.339(0.399) *$ & $0.296(0.042) *$ \\
\hline \multicolumn{4}{|l|}{ Before explosion: } \\
\hline Explosion $\times$ TimeM $_{-16}(2014.04)$ & $0.829(0.284)$ & $0.903(0.275)$ & \\
\hline Explosion $\times$ TimeM $_{-15}(2014.05)$ & $-0.144(0.383)$ & $0.100(0.288)$ & \\
\hline Explosion $\times$ TimeM $_{-14}(2014.06)$ & $-0.062(0.236)$ & $-0.103(0.227)$ & \\
\hline Explosion $\times$ TimeM $_{-13}$ (2014.07) & $0.073(0.141)$ & $0.254(0.131)$ & \\
\hline Explosion $\times$ TimeM $_{-12}(2014.08)$ & $-0.079(0.095)$ & $-0.063(0.081)$ & \\
\hline Explosion $\times$ TimeM $_{-11}(2014.09)$ & $-0.034(0.083)$ & $-0.047(0.067)$ & \\
\hline Explosion $\times$ TimeM $_{-10}(2014.10)$ & $0.166(0.084)$ & $0.165(0.068)$ & \\
\hline Explosion $\times$ TimeM_9 $_{-9}(2014.11)$ & $-0.025(0.088)$ & $-0.007(0.074)$ & \\
\hline Explosion $\times$ TimeM $_{-8}(2014.12)$ & $-0.056(0.081)$ & $-0.069(0.066)$ & \\
\hline Explosion $\times$ TimeM-7 $(2015.01)$ & $0.011(0.078)$ & $-0.018(0.065)$ & \\
\hline Explosion $\times$ TimeM $_{-6}(2015.02)$ & $-0.042(0.077)$ & $-0.038(0.061)$ & \\
\hline Explosion $\times$ TimeM-5 $_{-}(2015.03)$ & $-0.089(0.063)$ & $-0.115(0.218)$ & \\
\hline Explosion $\times$ TimeM $_{-4}(2015.04)$ & $-0.141(0.171)$ & $-0.161(0.336)$ & \\
\hline Explosion $\times$ TimeM$_{-3}(2015.05)$ & $-0.222(0.262)$ & $-0.239(0.315)$ & \\
\hline Explosion $\times$ TimeM-2 $_{-2}(2015.06)$ & $-0.124(0.272)$ & $-0.157(0.334)$ & \\
\hline Explosion $\times$ TimeM $_{-1}(2015.07)$ & $-0.280(0.286)$ & $-0.239(0.385)$ & \\
\hline Structural Attributes & Yes & Yes & Yes \\
\hline Environmental Attributes & Yes & Yes & Yes \\
\hline R-Squared & 0.6950 & 0.7087 & 0.6977 \\
\hline Adj R-Squared & 0.6938 & 0.7066 & 0.6969 \\
\hline F-statistics & $566.84^{* * *}$ & $343.21 * * *$ & $541.54^{* * *}$ \\
\hline
\end{tabular}

Note: ${ }^{*} p<0.05,{ }^{* *} p<0.01,{ }^{* * *} p<0.001$, the number in parentheses is the standard error of the estimated result. The dependent variable of the above three models is the logarithm of the property sales price. We drop the information of February 2014 (2014.02) and March 2014 (2014.03) in order to avoid the dummy trap. 


\subsection{Risk Perception of Home Buyers}

The estimation results of Model 3 in Table 5 demonstrate the dynamic treatment effect each month after the explosion event. The graphical presentation of the dynamic treatment effects is delineated in Figure 2. It is clear that the monthly dynamic treatment effects follow an upward trend. Almost all the monthly dynamic treatment effects are significant. For the first six months after the explosion, the monthly dynamic effects are negatively significant, ranging from -0.336 to -0.203 . Since then, the dynamic treatment effect move as an uprising trend and even climb up to a positive level. These findings suggest that home buyers are unwilling to/fear living within $5 \mathrm{~km}$ of the explosion site as they are worried about the unknown toxic chemical materials that penetrated in the soil and water of the Tianjin port explosion site in the first half-year after the explosion event. On 5 February 2016, the investigation of the Tianjin port explosion was officially announced by the China State Council [30]. The investigation report details the economic loss and measures that have been taken to reduce the impact of toxic chemical pollutants of the explosion event on the environment. The planning department of Tianjin city came up with a development scheme: rebuilding a harbor ecological park at the explosion site. Due to the difficulty and complexity of the remediation of the explosion site, the redevelopment project did not commence until August 2016 [31]. The announcement of redeveloping the explosion (hazardous) site as an ecological park is good news for the home buyers as the Tianjin government endeavors to turn urban disamenities into urban amenities, which would somehow help the home buyers to regain the confidence.

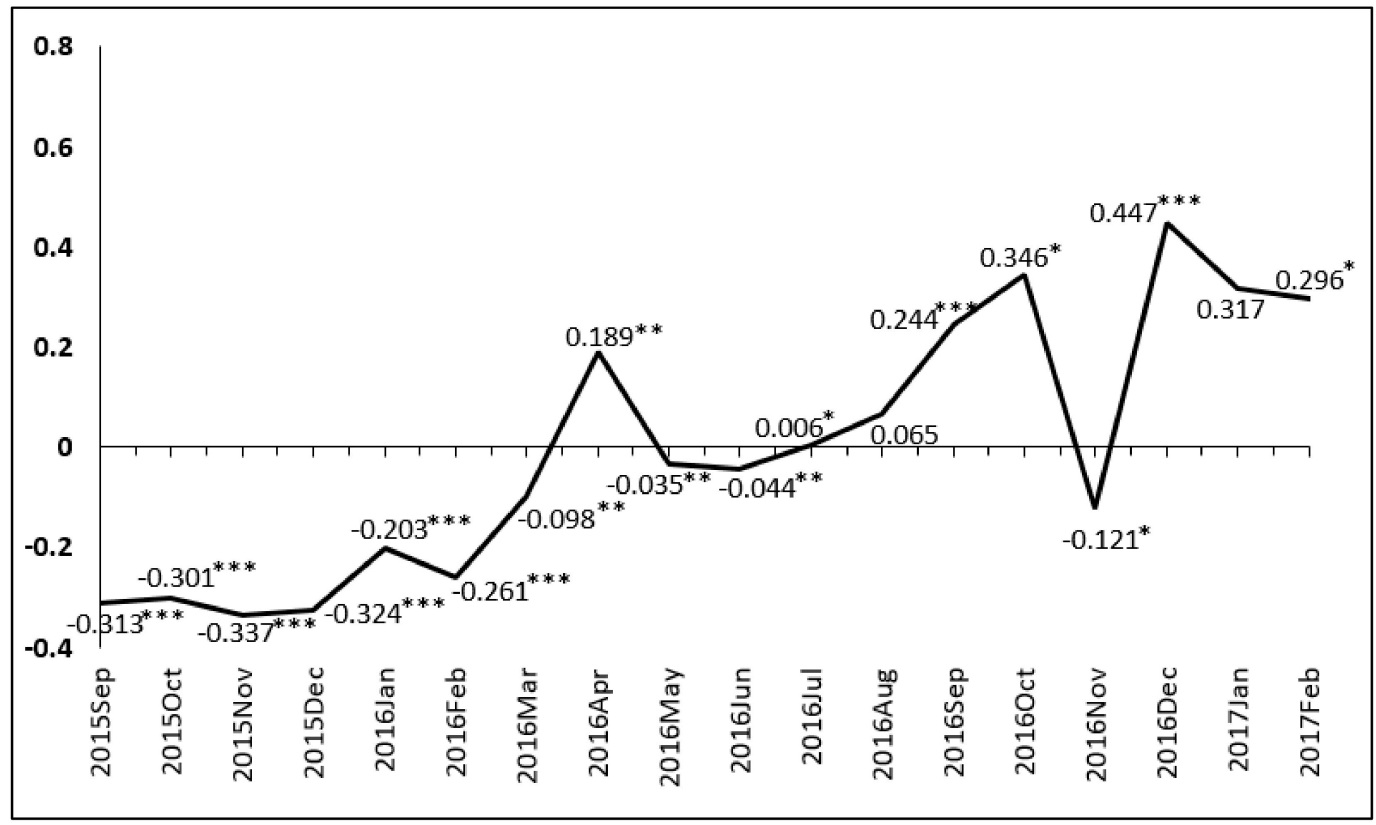

Figure 2. Dynamic lag treatment effects-perception of home buyers.

The soaring trend of the monthly dynamic effects is distinguished from the previous literature as regards risk perception of the extreme event on property value $[14,24,25]$. The possible explanation is that the official investigation report of the extreme event from China government is the most trustworthy source for Chinese citizens. They trust the arrangement of the Chinese government for hazardous site remediation and redeveloping the explosion site.

\subsection{Risk Perception of Home Sellers}

In addition to the empirical analysis for the buyers' preference and attitude towards environmental risk, we expect to investigate the effect of the explosion event on the home sellers. To investigate the risk perception of the home sellers, a ratio of property sales price to list price is utilized as a proxy for 
the empirical analysis. The statistical results are documented in Table 6 and Figure 3, where the results shown in Table 6 are the average treatment effects and the graphical presentation in Figure 3 is the monthly dynamic effects after the explosion event.

Table 6. Estimation of overreaction effects of the property seller.

\begin{tabular}{cccc}
\hline Variables & Model 1 & Model 2 & Model 3 \\
\hline Treatment effect & & & \\
\hline Time & $-0.032(0.024)^{* * *}$ & $-0.064(0.002)^{* *}$ & $-0.069(0.002)^{* *}$ \\
Explosion & $-0.136(0.004)^{* * *}$ & $-0.164(0.003)^{* * *}$ & $-0.126(0.004)^{* * *}$ \\
Explosion $\times$ Time & $-0.048(0.006)^{* * *}$ & $-0.028(0.004)^{* * *}$ & $-0.022(0.003)^{* * *}$ \\
Intercept & $0.965(0.002)^{* * *}$ & $0.587(0.008)^{* * *}$ & $0.448(0.066)^{* * *}$ \\
Structural attributes & No & Yes & Yes \\
Environmental attributes & No & No & Yes \\
\hline R-Squared & 0.3030 & 0.4627 & 0.4793 \\
Adj R-Squared & 0.3028 & 0.4623 & 0.4785 \\
F-statistics & $1728.61^{* * *}$ & $1283.62^{* * *}$ & $577.300^{* * *}$ \\
\hline
\end{tabular}

Note: ${ }^{*} p<0.05,{ }^{* *} p<0.01,{ }^{* * *} p<0.001$, the number in parentheses is the standard error of the estimated result. The dependent variable of the above three models is the logarithm of the ratio of the sales price to list price.

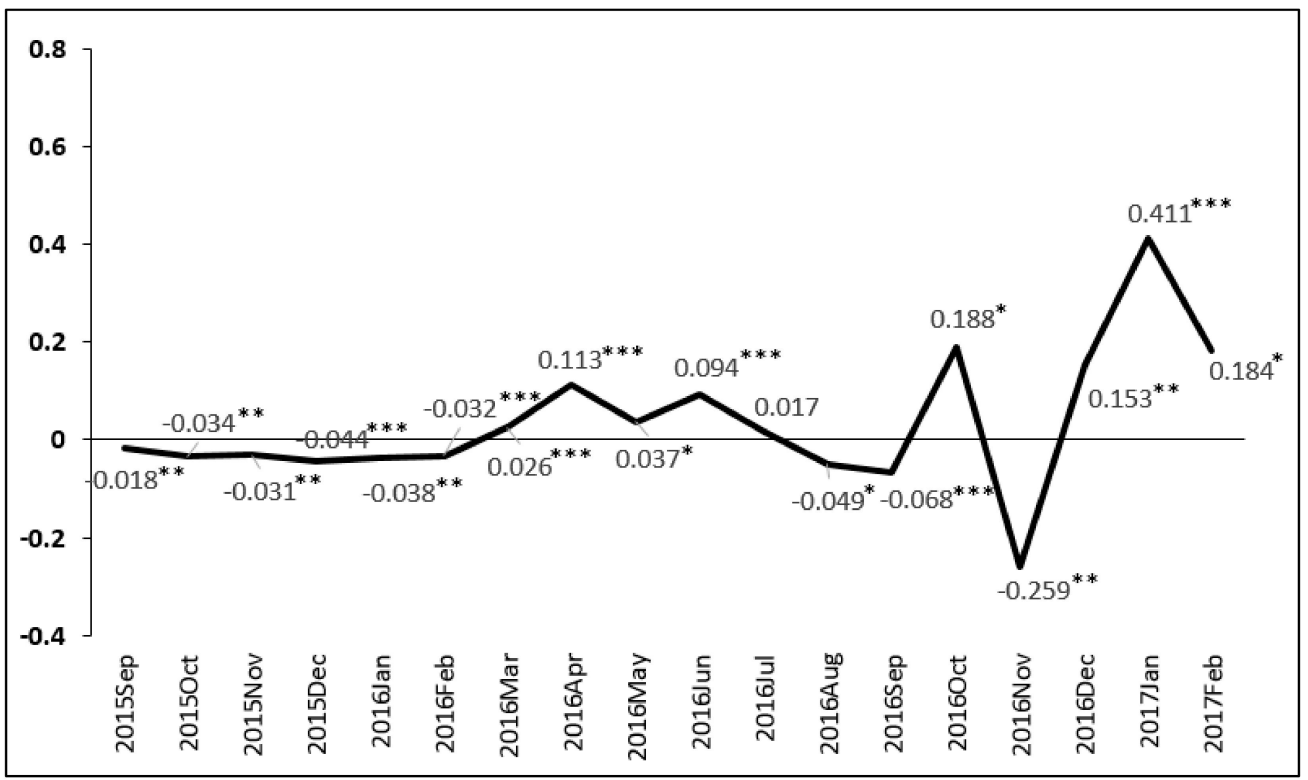

Figure 3. Graphical presentation of the monthly dynamic effect of the home seller.

The result of Model 1 in Table 6 is the baseline result. It is obvious to see that all the coefficients are statistically significant. Similarly to the empirical findings above, the coefficient of goodness-of-fit increases provided that the control variables (e.g., structural attributes and environmental attributes) are considered in the model. Having controlled the covariates (Model 3 in Table 6), the estimated coefficients of average treatment effects are stable, which are around -0.022 . This suggests that the loss-averse home sellers compromise to the potential buyers during the bargaining period by lowering the reservation price and accept the relative low offering price from the potential buyer in order to make its property a quick sale.

To further investigate the extent/degree the home sellers compromise to the potential buyers in the home selling process, another regression model (i.e., Equation (4)) is employed by considering the monthly dynamic treatment effects of the sale-to-list ratio. To save place and make the pattern of dynamic effects easy to understand and capture, the monthly dynamic treatment effects are illustrated in Figure 3. Unlike the monthly dynamic treatment effects of home buyers towards an increasing trend, 
the trend of that of home sellers seems to be steady at the outset, and half a year later, starts to fluctuate. For the first six months, the monthly treatment effects are statistically and significantly associated with a negative coefficient ranging from -0.018 to -0.044 . This reveals that the home sellers were panicked after the explosion and urged to sell the property. Without knowing the investigation report from the Chinese government, the home sellers confronted the unknown risk, where they are afraid that the damage of the explosion on the environment may be irreversible. Under these circumstances, the home sellers are loss averse sellers who intend to set a relatively high list price in order to attenuate the prospective loss though, yet they have to make a quick decision on seeing the offering from the potential buyers with low price. This group of loss averse home sellers finally accepts the low price offering in the case for a long time waiting to sell the properties.

After the first six months, the dynamic effect started to climb up and was maintained at a positive level for five months, then returned to a negative level and was more fluctuated than previous periods. This is possibly because the official investigation report has been available to the public since February 2016 and the Chinese government announced a series of schemes for rebuilding and rehabilitating the explosion site, both of which delivered the information to the homeowners that the hazardous environment was not permanently damaged and the government was trying its best to turn environmental disamenities into urban amenities. The appearance of the fluctuation of the monthly dynamic effects could be ascribed to the inconsistency of home sellers' attitudes towards the progress of remediating the explosion site, which is illustrated in Figure 3. The complexity and difficulty of the explosion site remediation work, the redevelopment scheme has to be postponed and rescheduled. Some home sellers are afraid of being exposed to and suffer a long-time environmental hazardous risk so that they made a quick disposition of the property and move far away from the explosion site. By grouping the results of Table 6 and Figure 3 together, the progression of dynamic effects reflects those home sellers within $5 \mathrm{~km}$ of the explosion site overreacted to the explosion event in the first six months and decays afterward.

The business implication is simply that if the risk perception of property investors affects transaction prices due to major accidents and disasters, then buyers and sellers should take advantage of such effects in the selection of counterparts in the sales and purchase process. After all, we document that such effects can explain a large part (as much as property characteristics) of the variation in transaction prices once we account for market conditions. We believe that policy implications are also important in this study. The regional property market may not be well functioning after a major accident and disaster. A local government can interfere in private voluntary negotiations by weakening the correlations between the port accident and the perceived negative risk for property buyers and sellers, especially when our results could be taken to suggest that local property investors are at a disadvantage.

\section{Conclusions}

The Tianjin port explosion created massive damage and a miserable nightmare for the citizens in Tianjin city. This man-made disaster turned the residential areas with favorable sea and harbor views into a hazardous site, leaking the poison pollutants to threaten the health of people physically and psychologically. This paper aimed to investigate the impact of the Tianjin port explosion on the risk perception of the public, where the willingness to pay for the property is used as an indicator to measure the public's risk perception. In addition to focusing on the buyers' risk perception, this paper also considers the risk perception of property sellers by considering a proxy sale-to-list ratio, which has been overlooked in the existing literature. The empirical analysis is conducted by using a set of second-hand domestic housing transaction records before and after the Tianjin port explosion event.

Our empirical results show that the average property price near the explosion site would drop $24 \%$ after the explosion event, which is in line with the rich set of previous studies that the property price is negatively associated with hazard events. However, the price of the property near the explosion site relative to the property far away from the explosion site does not remain as negative for a long period 
after the explosion event. In fact, it jumps to a positive level with a short decline for a few months and reverts back to a positive level. We found that the estimation results reflect the increased risk perception of home buyers regarding of closer to the explosion site in the first half-year and afterward, the fear dissipated over time.

On the other hand, the risk perception level of the property sellers was investigated by considering the sale-to-list ratio. The adoption of this ratio could well reflect the degree/the extension to which the seller should compromise in the process of negotiating with potential buyers. The overall results show that the sale-to-list ratio would decrease by $2.2 \%$ if the property was near the explosion site. The sale-to-list ratio of the properties near the explosion site relative to the properties far away from the explosion site was detected to decrease for the first six months after the explosion event, then climb to a positive level for five months, then wandering back and forth between the positive and negative levels. The findings indicate that home sellers near the explosion site are panicked and eager to sell their property quickly within a short period.

Combining the results of buyers' and sellers' perspective, we find that the negative impact of the Tianjin port explosion on the public mainly clustered in the first six months, which provides evidence of the overreaction from the public. The overreaction of the public drove the Chinese government immediately responded to the extreme event by launching a series of policies for strengthening the safety port management and improving the safety level of storing the hazardous and dangerous toxic chemical materials, resulting in the overreaction of public decays/dissipate over time.

The limitation of this research lies in the following dimensions, which could be potentially fruitful directions for future research. In the first place, the sample data only limit in housing transactions, where the indicator-time on the market (TOM) is not considered in this paper. TOM is a useful indicator to measure the duration of time a residential unit/apartment is available on the market until it is rent out $[32,33]$. The consideration of TOM would provide an alternative angle to analyze how home buyers and sellers react to the Tianjin port explosion. In the second place, public media data are not covered in this study. By collecting the data from public media, the overreaction of the public in response to the event of the port accident can be further explored. In the third place, the interaction between buyers (or sellers) is not considered in this study. On confronting an extreme event like the Tianjin port explosion, the home buyers and home sellers will not make the home buying or selling decision independently. Instead, these two parties are influenced by each other. Therefore, the models that incorporate spatial interactions, such as spatial econometric models, should be used for future studies. In the fourth place, the data regarding health, environment (e.g., air quality, water quality, soil quality) and remedy of hazardous explosion zone have not yet been considered. Future work should include this information to measure the impact of a port accident on the environment.

Author Contributions: This paper was conducted by Y.H., T.L.Y. and C.L. Y.H. contributed to research idea initiation and draft the first version of the manuscript. T.L.Y. contributed to the research methods and research design. C.L. contributed to data collection and data analysis. All authors have read and agreed to the published version of the manuscript.

Funding: This research was funded by The Hong Kong Polytechnic University grant number G-YBTM (P0009561) and 1-YW3L (P0000319).

Acknowledgments: There authors thank the guest editors, Dr Kum Fai Yuen and Dr Yiik Diew Wong and three referees for their critical comments and helpful suggestions. This paper is a substantially revised and extended version of a paper presented at 2018 World Transport Convention, Beijing, China.

Conflicts of Interest: The authors declare no conflict of interest.

\section{References}

1. Yu, M.; Lv, Q.; Ding, H.; Zeng, X.; Cao, J.; Liu, J.; Fan, H.; Hou, S. Evaluation of blast injury patients from the 2015 Tianjin explosions in China. Burns 2016, 42, 1133-1140. [CrossRef]

2. Huang, P.; Zhang, J. Facts related to August 12, 2015 explosion accident in Tianjin, China. Process. Saf. Prog. 2015, 34, 313-314. [CrossRef] 
3. Li, J.; Tian, B. Refined locations of major explosions in Tianjin Harbor. Sci. Bull. 2015, 60, $1868-1870$. [CrossRef]

4. Analysis of Tianjin Port Explosion: Risk management is the Key. Available online: http://www.swissre.com/ china/Analysis_of_Tianjin_Port_Explosion.html (accessed on 22 November 2019).

5. Tianjin Explosions Were Result of Mismanagement, China Finds. Available online: https://www.nytimes. com/2016/02/06/world/asia/tianjin-explosions-were-result-of-mismanagement-china-finds.html (accessed on 23 November 2019).

6. Zhang, J.-J.; Wang, T.-B.; Fan, D.; Zhang, J.; Jiang, B.-G. Medical Response to the Tianjin Explosions: Lessons Learned. Disaster Med. Public Heal. Prep. 2017, 12, 411-414. [CrossRef]

7. Genesove, D.; Mayer, C. Loss aversion and seller behavior: Evidence from the housing market. Q. J. Econ. 2001, 116, 1233-1260. [CrossRef]

8. Slovic, P. The Perception of Risk. In Scientists Making a Difference; Cambridge University Press: New York, NY, USA, 2016; pp. 179-182.

9. Slovic, P.; Flynn, J.; Mertz, C.K.; Poumadére, M.; Mays, C. Nuclear Power and the Public. In Cross-Cultural Risk Perception; Springer Science and Business Media LLC: Berlin, Germany, 2000; pp. 55-102.

10. Slovic, P. Perception of risk. Science 1987, 236, 280-285. [CrossRef]

11. Yamane, F.; Ohgaki, H.; Asano, K. The Immediate Impact of the Fukushima Daiichi Accident on Local Property Values. Risk Anal. 2013, 33, 2023-2040. [CrossRef] [PubMed]

12. Atreya, A.; Ferreira, S. Seeing is believing? Evidence from property prices in inundated areas. Risk Anal. 2015, 35, 828-848. [CrossRef]

13. Muehlenbachs, L.; Spiller, E.; Timmins, C. The Housing Market Impacts of Shale Gas Development. Am. Econ. Rev. 2015, 105, 3633-3659. [CrossRef]

14. Bauer, T.K.; Braun, S.T.; Kvasnicka, M. Nuclear power plant closures and local housing values: Evidence from Fukushima and the German housing market. J. Urban Econ. 2017, 99, 94-106. [CrossRef]

15. Beltrán, A.; Maddison, D.; Elliott, R.J.R. Assessing the Economic Benefits of Flood Defenses: A Repeat-Sales Approach. Risk Anal. 2018, 38, 2340-2367. [CrossRef] [PubMed]

16. Kahneman, D.; Tversky, A. Prospect theory: An analysis of decision under risk. Econometrica 1979, 47, 363-391. [CrossRef]

17. Hall, A.H.; Rumack, B.H. Clinical toxicology of cyanide. Ann. Emerg. Med. 1986, 15, 1067-1074. [CrossRef]

18. Freybote, J.; Fruits, E. Perceived environmental risk, media, and residential sales prices. J. Real Estate Res. 2015, 37, 217-244.

19. Haurin, D.R.; Haurin, J.L.; Nadauld, T.; Sanders, A. List Prices, Sale Prices and Marketing Time: An Application to U.S. Housing Markets. Real Estate Econ. 2010, 38, 659-685. [CrossRef]

20. McCluskey, J.J.; Rausser, G.C. Estimation of Perceived Risk and Its Effect on Property Values. Land Econ. 2001, 77, 42. [CrossRef]

21. Kousky, C. Learning from Extreme Events: Risk Perceptions after the Flood. Land Econ. 2010, 86, $395-422$. [CrossRef]

22. Votsis, A.; Perrels, A. Housing prices and the public disclosure of flood risk: a difference-in-differences analysis in Finland. J. Real Estate Financ. Econ. 2016, 53, 450-471. [CrossRef]

23. Zhu, H.; Deng, Y.; Zhu, R.; He, X. Fear of nuclear power? Evidence from Fukushima nuclear accident and land markets in China. Reg. Sci. Urban Econ. 2016, 60, 139-154. [CrossRef]

24. Hansen, J.L.; Benson, E.D.; Hagen, D.A. Environmental Hazards and Residential Property Values: Evidence from a Major Pipeline Event. Land Econ. 2006, 82, 529-541. [CrossRef]

25. Deng, G.; Gan, L.; Hernandez, M.A. Do natural disasters cause an excessive fear of heights? Evidence from the Wenchuan earthquake. J. Urban Econ. 2015, 90, 79-89. [CrossRef]

26. Wong, G. Has SARS infected the property market? Evidence from Hong Kong. J. Urban Econ. 2008, 63, 74-95. [CrossRef]

27. Angrist, J.D.; Pischke, J.S. Mostly Harmless Econometrics: An Empiricist's Companion; Princeton University Press: Princeton, NJ, USA, 2008; pp. 227-243.

28. Smolen, G.; Moore, G.; Conway, L. Economic effects of hazardous chemical and proposed radioactive waste landfills on surrounding real estate values. J. Real Estate Res. 1992, 7, 283-295.

29. How much loss of Tianjin Explosion. 2015. Available online: http://www.bbc.com/zhongwen/simp/china/ 2015/08/150814_tianjin_explosion_impact (accessed on 22 November 2019). (In Chinese) 
30. CSC (China State Council). Investigation Report of Tianjin port "8.12" Explosion Event and Ruihai Company Storing Dangerous Goods in Warehouse. Available online: http://www.gov.cn/foot/2016-02/05/5039788/files/ 460731d8cb4c4488be3bb0c218f8b527.pdf (accessed on 24 November 2019). (In Chinese)

31. MNW (Min Nan Wang). One Year after the Tianjin Explosion-2016. Available online: http://www.mnw.cn/ news/china/1306762.html (accessed on 2 December 2019). (In Chinese)

32. Huang, Y. A study of sub-divided units (SDUs) in Hong Kong rental market. Habitat Int. 2017, 62, 43-50. [CrossRef]

33. Liang, C.; Hui, E.C.; Yip, T.L. Time on market (TOM): The impact of new residential stamp duty. Phys. A: Stat. Mech. its Appl. 2018, 503, 1117-1130. [CrossRef]

(C) 2020 by the authors. Licensee MDPI, Basel, Switzerland. This article is an open access article distributed under the terms and conditions of the Creative Commons Attribution (CC BY) license (http://creativecommons.org/licenses/by/4.0/). 